\title{
150-kD Oxygen-regulated Protein Is Expressed in Human Atherosclerotic Plaques and Allows Mononuclear Phagocytes to Withstand Cellular Stress on Exposure to Hypoxia and Modified Low Density Lipoprotein
}

\author{
Yoshitane Tsukamoto, ${ }^{\ddagger}$ Keisuke Kuwabara, ${ }^{\ddagger}$ Seiichi Hirota, ${ }^{*}$ Jun Ikeda, ${ }^{\S}$ David Stern,, Hideki Yanagi, ${ }^{\S}$ Masayasu Matsumoto, ${ }^{\ddagger}$ \\ Satoshi Ogawa, ${ }^{\ddagger}$ and Yukihiko Kitamura* \\ $*$ Department of Pathology, and ${ }^{\ddagger}$ First Department of Medicine, Osaka University Medical School, Suita City, 565 Japan; ${ }^{\circledR}$ HSP Research \\ Institute, Kyoto 600, Japan; and ${ }^{\|}$Department of Physiology and Cellular Biophysics, College of Physicians and Surgeons, Columbia \\ University, New York, New York 10032
}

\begin{abstract}
The 150-kD oxygen-regulated protein (ORP150) was initially characterized based on its selective expression in astrocytes subjected to oxygen deprivation (Kuwabara, K., M. Matsumoto, J. Ikeda, O. Hori, S. Ogawa, Y. Maeda, K. Kitagawa, N. Imuta, K. Kinoshita, D.M. Stern, et al. 1996. J. Biol. Chem. 279:5025-5032). We have found that exposure of cultured human aortic smooth muscle cells and mononuclear phagocytes (MPs) to hypoxia $\left(\mathrm{pO}_{2} \sim 12-14\right.$ torr) induces ORP150 transcripts and production of the antigen, whereas incubation with either hydrogen peroxide, sodium arsenite, heat shock, or 2-deoxyglucose was without effect. Tissue extracts prepared from human atherosclerotic lesions demonstrated expression of ORP150 mRNA and antigen, vs lack of ORP150 in samples from nonatherosclerotic areas. In situ hybridization using ORP150 riboprobes showed the mRNA to be predominately present in macrophages in atherosclerotic plaques. Furthermore, autoantibody to ORP150 was demonstrated in the serum of patients with severe atherosclerosis, consistent with inducible in vivo expression of ORP150. Introduction of antisense oligonucleotide for ORP150 selectively diminished hypoxia-mediated induction of ORP150 antigen and reduced the viability of hypoxic MPs, especially in the presence of modified (oxidized/acetylated) LDL. In support of a role for ORP150 in the MPs' response to the microenvironment of an atheroma, the presence of oxidized LDL enhanced by $\sim 10$-fold ORP150 expression in hypoxic cultures. These data indicate that cells of the atherosclerotic vessel wall express ORP150 as part of a protective mechanism, potentially triggered by local hypoxia/hypoxemia and augmented by modified lipoproteins. The presence of antibody to ORP150 in sera of patients with severe atherosclerosis emphasizes the possibility that ORP150 may be a marker of vascular pathology. $(J$. Clin. Invest. 1996. 98:1930-1941.) Key words: atherosclerosis $\bullet$ smooth muscle cell $\bullet$ macrophage $\cdot$ stress response
\end{abstract}

Address correspondence to Satoshi Ogawa, Department of Anatomy and Neuroscience, Osaka University Medical School, 2-2 Yamadaoka Suita City, 565 Japan. Phone: 81-6-879-3221; FAX: 81-6-8793229; E-mail: QZA03417@niftyserve.or.jp

Received for publication 15 May 1996 and accepted in revised form 14 August 1996.

J. Clin. Invest.

(C) The American Society for Clinical Investigation, Inc. 0021-9738/96/10/1930/12 \$2.00

Volume 98, Number 8, October 1996, 1930-1941

\section{Introduction}

The cellular response to oxygen deprivation involves redirection of biosynthetic mechanisms with expression of a set of polypeptides termed oxygen-regulated proteins (ORPs) ${ }^{1}(1)$. Such stress proteins induced by hypoxia can overlap with those synthesized in response to glucose deprivation and heat shock. For example, a 78-kD polypeptide induced by hypoxia/reoxygenation in cultured astrocytes is identical to glucose-regulated protein 78 , and functions as a molecular chaperone to facilitate elaboration of a neurotrophic cytokine, interleukin $6(2,3)$. Induction of heat shock protein (HSP) 70, shown to have a protective function in a gerbil forebrain ischemia model (4), also occurs in response to hypoxia followed by replacement into normoxia.

Recently, we isolated and cloned a novel $150-\mathrm{kD}$ polypeptide termed oxygen-regulated protein (ORP150) that is induced in astrocytes by hypoxia. This polypeptide is localized in the endoplasmic reticulum, suggesting that it may participate in protein folding and/or translocation in response to environmental stress. In contrast with many other ORPs, which overlap with HSPs and glucose-regulated protein, synthesis of the 150-kD polypeptide was only triggered by hypoxia, not by glucose deprivation, heat shock, or multiple other stimuli (5). This leads us to propose that expression of ORP150 is more closely tied to oxygen depletion or cellular events initiated in this situation. In the current study, we demonstrate expression of this novel stress protein in human atherosclerotic plaques, especially in mononuclear phagocytes. Biosynthesis of ORP150 in cultured monocyte-derived macrophages exposed to hypoxia is potentiated by $\sim 10$-fold in the presence of modified lipoproteins. Furthermore, suppression of ORP150 expression markedly attenuated survival of mononuclear phagocytes under hypoxic conditions in the presence of modified lipoproteins. Consistent with the presence of ORP150 in abnormal vasculature, sera from patients with severe atherosclerosis showed the presence of IgG reactive with ORP150 by immunoblotting. These data lead us to suggest that ORP150 is a component of the protective response of macrophages to environmental stress, in this instance the combination of modified lipoproteins and possible concomitant hypoxia.

1. Abbreviations used in this paper: $1 \mathrm{~A} 4$, monoclonal antibody to $\alpha$-smooth muscle actin; Ac-LDL, acetylated LDL; HSP, heat shock protein; LDH, lactate dehydrogenase; MP, mononuclear phagocyte; ORP, oxygen-regulated protein; Ox-LDL, oxidized LDL; SMC, smooth muscle cell. 


\section{Methods}

Cell culture and induction of hypoxia. Human peripheral bloodderived mononuclear phagocytes (MPs) were prepared as described (6). In brief, the mononuclear cell fraction was separated by density gradient centrifugation (Histopaque 1077; Sigma Chemical Co., St. Louis, MO) followed by adherence to tissue culture plasticware for $4 \mathrm{~h}$ at $37^{\circ} \mathrm{C}$. Adherent cells were cultured for $10-14 \mathrm{~d}$ in RPMI 1640 (Gibco Laboratories, Grand Island, NY) containing human serum $(10 \%)$ and penicillin/streptomycin $(100 \mathrm{U} / \mathrm{ml}, 100 \mu \mathrm{g} / \mathrm{ml})$. Human aortic smooth muscle cells (SMCs) were purchased from KURABO (Osaka, Japan) and cultured in S-BM medium (KURABO) containing recombinant human basic fibroblast growth factor $(2 \mathrm{ng} / \mathrm{ml})$, recombinant human EGF $(10 \mathrm{ng} / \mathrm{ml})$, gentamicin $(50 \mu \mathrm{g} / \mathrm{ml})$, amphoterin-B (amphotericin B, $50 \mathrm{ng} / \mathrm{ml})$, dexamethasone $(0.39 \mu \mathrm{g} / \mathrm{ml})$, and FCS (5\%). SMCs used for experiments were at passage 5. When cultures achieved confluence, they were exposed to hypoxia using an incubator attached to a hypoxia chamber that maintained a humidified atmosphere with low oxygen tension $\left(\mathrm{pO}_{2}, 12-14\right.$ torr; Coy Laboratory Products, Ann Arbor, MI) as described previously (7). Where indicated, after exposure to hypoxia, cultures were returned to the ambient atmosphere (reoxygenation), at which time the conditioned medium was rapidly exchanged with fresh medium. Oxygen tension in the medium was measured using a blood gas analyzer (ABL-2; Radiometer, Sweden). Cell viability was assessed by morphological criteria, trypan blue exclusion, lactate dehydrogenase (LDH) release, and general protein synthesis measured by the incorporation of $\left[{ }^{3} \mathrm{H}\right]$ leucine to trichloroacetic acid-precipitable material (8).

Modification of $L D L$. Modification of native LDL was performed as described. In brief, acetylated LDL (Ac-LDL) was prepared by incubating human LDL with acetic anhydride at $4^{\circ} \mathrm{C}$ overnight as described (9). Oxidized LDL (Ox-LDL) was prepared by incubating $\mathrm{LDL}$ at $180 \mu \mathrm{g} / \mathrm{ml}$ in $5 \mu \mathrm{M} \mathrm{CuSO}_{4}$ for $24 \mathrm{~h}$ at $37^{\circ} \mathrm{C} \mathrm{(10).}$ Ac-LDL and Ox-LDL were characterized by SDS-PAGE (11), agarose gel electrophoresis, immunoblotting, and quantification of thiobarbituric acid-reactive substances. Based on these criteria, our preparations of Ac-LDL and Ox-LDL conformed to what has been observed previously $(12,13)$.

Preparation of anti-ORP150 antibody and immunoblotting. A peptide was synthesized based on the $\mathrm{NH}_{2}$-terminal 15 amino acids obtained from purified rat ORP150 (5). This sequence is identical to the predicted $\mathrm{NH}_{2}$-terminal amino acid sequence of human ORP150 deduced from the human cDNA (Ikeda, J., H. Yanagi, K. Kuwabara, S. Ogawa, M. Matsumoto, and Y. Yura, manuscript in preparation [Genbank No. U41853]). Synthetic peptide was aggregated by the Multiple Antigen Peptide method (Sawadie Technology Inc., Tokyo, Japan; reference 14) and used to immunize rabbits as described (15). Animals received a second immunization at $4 \mathrm{wk}, 1$ mo later, immune serum was harvested and $\mathrm{IgG}$ was prepared by affinity chromatography using immobilized protein A (Econopack; Bio-Rad Laboratories, Hercules, CA). The titer of antiserum raised against the $\mathrm{NH}_{2}$-terminal ORP150 synthetic peptide was assessed by the ELISA. Protein concentration was measured by the protein assay (Bio-Rad Laboratories) after overnight dialysis vs PBS ( $\sim 1 \mathrm{mg} / \mathrm{ml}$ in each case).

Induction of ORP150 antigen was analyzed by immunoblotting with anti-human ORP150 IgG by the method of Towbin et al. (16). In brief, U373 cells (a human glioma cell line, kindly provided by Prof. Hirano, Osaka University, Japan), Hela cells (American Tissue Culture Collection, Rockville, MD), human aortic SMCs and MPs were cultured to a density of $\sim 10^{6}$ cells, and then exposed to hypoxia. At the indicated time points, cells were harvested, pelletted by centrifugation, and lysed in phosphate-buffered saline containing NP-40 (1\%) and EDTA (5 mM). Then, after determination of protein content (17), the indicated amount of each sample was subjected to SDS-PAGE (11) and immunoreactive material was detected by incubation with anti-human ORP150 IgG $(5 \mu \mathrm{g} / \mathrm{ml})$ followed by horseradish peroxidase-conjugated secondary antibody (Sigma Chemical Co.). Where indicated, either native LDL, Ac-LDL, Ox-LDL, LPS, or $\gamma$-interferon (Sigma Chemical Co.) was added to cultures media with no serum, and cells were further incubated in either hypoxic or normoxic condition for $8 \mathrm{~h}$ before harvest (18).

To assess the effect of chemical stress on induction of ORP150, cultured MPs were either exposed to 2-deoxyglucose, heat shock, hydrogen peroxide, or cobalt chloride for the indicated times at normoxic condition. Cells were washed with PBS and subjected to Western blotting as above.

To determine the specificity of anti-human ORP150 IgG raised to the synthetic peptide for detection of intact ORP150, immunoadsorption using anti-ORP150 IgG raised against purified rat ORP150 was employed as described (5). In brief, protein extract was prepared from U373 cells $\left(\sim 5 \times 10^{8}\right)$ exposed to hypoxia for $48 \mathrm{~h}$ by treatment with Tris-buffered saline $(\sim 12 \mathrm{ml})$ containing NP-40 (1\%), EDTA $(5 \mathrm{mM})$, and PMSF $(1 \mathrm{mM})$ for $12 \mathrm{~h}$ at $4^{\circ} \mathrm{C}$ with either anti-rat ORP150 IgG or preimmune IgG (1:50 dilution, $20 \mu \mathrm{g} / \mathrm{ml}$ in each case). Then, a suspension of Staphylococcus aureus protein A $(0.4 \mathrm{ml} /$ tube, $10 \%$ suspension of IgGSorb; The Enzyme Center, Malden, MA) was added to each tube and incubated for $1 \mathrm{~h}$ at $4^{\circ} \mathrm{C}$. After centrifugation $(4,000 \mathrm{rpm}$ for $10 \mathrm{~min})$, the supernatant was collected, concentrated 50 fold by ultrafiltration, an aliquot $(20 \mu$ l containing $\sim 10 \mu \mathrm{g}$ protein) was subjected to Western blotting, and membranes were reacted with anti-human ORP150 IgG raised to the human ORP150 synthetic peptide.

Northern analysis of cultured vascular cells. To assess expression of ORP150 transcripts, Northern analysis was performed using a ${ }^{32} \mathrm{P}$-labeled probe comprising a partial rat ORP150 cDNA corresponding to basepairs 151-381 (deduced amino acid residues 51-127) (5). Total RNA ( $\sim 10 \mu \mathrm{g})$ was extracted from either aortic SMCs or MPs exposed to hypoxia or hypoxia/reoxygenation for the indicated times as described (19). RNA was separated by agarose gel (1\%) electrophoresis, transferred overnight onto Hybond $\mathrm{N}+$ (Amersham International, Little Chalfont, UK), and then fixed to the membrane by ultraviolet irradiation before hybridization. The membrane was prehybridized for $3 \mathrm{~h}$ at $50^{\circ} \mathrm{C}$ in hybridization buffer $(0.9 \mathrm{M} \mathrm{NaCl}$, $90 \mathrm{mM}$ sodium citrate, $\mathrm{pH} 7.0)$ containing $5 \times$ Denhardt's solution, SDS $(0.5 \%)$, and heat-denatured salmon sperm DNA $(100 \mu \mathrm{g} / \mathrm{ml})$. A rat ORP150 cDNA was radiolabeled with $\left[{ }^{32} \mathrm{P}\right] d \mathrm{CTP}$ (DuPont-NEN, Boston, MA) by the random primer procedure (Megaprime DNA Labelling System, UK). After hybridization overnight at $50^{\circ} \mathrm{C}$ in hybridization buffer containing radiolabeled cDNA probe, filters were washed twice with $2 \times \mathrm{SSC} / 0.1 \%$ SDS and $0.2 \times \mathrm{SSC} / 0.1 \%$ SDS for $30 \mathrm{~min}$ at $50^{\circ} \mathrm{C}$, exposed to $\mathrm{x}$-ray film (Eastman Kodak Co., Rochester, NY), and subjected to autoradiography. The level of ORP150 mRNA was evaluated by the comparison with $\beta$-actin mRNA. To assess the effect of oxidized LDL or lipopolysaccharide on MPs, cultures were exposed to normoxia or hypoxia, and these agents were added $8 \mathrm{~h}$ before harvest. Total RNA was then extracted and subjected to Northern blotting as described above.

Preparation of human tissues. In accordance with our approved human investigation protocol from the Osaka University Hospital Ethics Review Board (Osaka, Japan), all specimens of human aortae and coronary arteries were obtained from autopsy cases within 1 to $4 \mathrm{~h}$ of death (18 individuals aged 1-83-yr-old). Specimens were divided into two categories based on macroscopic inspection: either nonatherosclerotic lesions (early lesions but no atheromatous plaques), or atherosclerotic lesions (advanced lesions with apparent atheromatous plaques) (20). Tissue samples for RNA extraction were frozen at $-80^{\circ} \mathrm{C}$ until use, and those for in situ hybridization and immunohistochemistry were fixed with $4 \%$ paraformaldehyde in $0.1 \mathrm{M}$ phosphate buffer, $\mathrm{pH} 7.0$, and embedded in paraffin. Serial sections $(3 \mu \mathrm{m})$ were cut from either thoracic or coronary artery and subjected to further experiments.

Detection of ORP150 antigen and mRNA in human aortae. Human aortae were washed with phosphate-buffered saline and aortic tissue was disrupted using a Polytron homogenizer in buffer containing NP-40 (1\%), EDTA (5 mM), PMSF (1 mM), leupeptin $(10 \mu \mathrm{g} / \mathrm{ml})$, and aprotinin $(10 \mu \mathrm{g} / \mathrm{ml})$ at $4^{\circ} \mathrm{C}$. After acetone precipitation, protein 
extracts were resuspended in PBS containing NP-40 (1\%), and immunoblotting was performed with monoclonal antibody to $\alpha$-smooth muscle actin (1A4) (21). Protein content was adjusted such that approximately the same amount of $\alpha$-smooth muscle actin was detected in each sample (total protein content was also comparable between samples), and the presence of immunoreactive ORP150 was assessed by Western blotting using anti-human ORP150 IgG $(5 \mu \mathrm{g} / \mathrm{ml})$.

Total RNA was extracted from aortic tissue as above (19). After the purification of RNA, the quality of RNA was examined by Northern blot analysis and hybridization with a human $\beta$-actin probe. RNA samples that failed to show a $\beta$-actin band were excluded from further experiments. For Northern blotting, total RNA $(10 \mu \mathrm{g})$ was fractionated in agarose gel (1\%) electrophoresis and transferred to Hybond $\mathrm{N}+$ nylon membrane. Membranes were prehybridized and then hybridized with the $\left.\alpha-{ }^{32} \mathrm{P}\right] d \mathrm{CTP}-$ labeled rat ORP150 cDNA fragment. After hybridization, the membranes were washed and signals were detected by autoradiography.

Laser densitometric analysis. Where indicated, laser densitometric analysis was performed to standardize results of Western and Northern blots. Autoradiograms from either Western or Northern blots were scanned with a laser densitometer and density of the corresponding bands was further analyzed with Quality One software (pdi, Huntington Station, NY).

In situ hybridization analysis of ORP150 in human atherosclerotic plaques. A rat ORP150 cDNA fragment (151-381) was subcloned into the EcoRV site of pBluescript KS(-) vector (Stratagene Inc., La Jolla, CA) and the sequence was confirmed as described (22). After linearization of the plasmid, digoxigenin-labeled single-stranded RNA was synthesized by T7 and T3 RNA polymerase with digoxigeninUTP and unlabeled ATP, GTP, and CTP. Details of the in situ hybridization protocol have been described (23). Hybridization of ORP150 mRNA was performed at $50^{\circ} \mathrm{C}$ for $16 \mathrm{~h}$, and signals were localized using a Nucleic Acid Detection Kit (Boehringer Mannheim, Mannheim, Germany). Controls included: (a) hybridization with sense probe; (b) RNase treatment before hybridization; and (c) use of neither the antisense RNA probe nor the antidigoxigenin antibody.

Immunohistochemical analysis of ORP150 in aortic samples. Immunohistochemistry was carried out as described previously (23). Sections were incubated in $\mathrm{H}_{2} \mathrm{O}_{2}(0.3 \%)$ in methanol for $30 \mathrm{~min}$, followed by washing in phosphate-buffered saline $(0.01 \mathrm{M})$ and treatment with normal mouse serum $(1 \%)$ for $30 \mathrm{~min}$ at room temperature to block nonspecific binding. Slides were then incubated with the primary antibodies for $18 \mathrm{~h}$ at $4^{\circ} \mathrm{C}$; mouse mAbs 1A4 (21) and PG-M1 (anti-CD68) (24) (DAKO SA, Glostrup, Denmark). Binding of mAbs was demonstrated using Vectostain ABC KIT (Vector Laboratories, Inc., Burlingame, CA). Sections were incubated with either nonimmune mouse serum instead of the primary antibody or with phosphate-buffered saline instead of the secondary antibody as negative controls.

Effect of human ORP150 antisense oligonucleotide on the viability of MPs. Three antisense 20-mer phosphorothioate oligonucleotides corresponding to three different structures around the initiation codon (named BK-59, 60, and 61) were synthesized (Yuki Gosei Kogyo Co., Ltd., Japan) and used as described (25). The effect of these oligonucleotides on expression of ORP150 was assessed by immunoblotting of MP extracts after exposure to hypoxia for $24 \mathrm{~h}$ in the presence of either oligonucleotides (20 $\mathrm{mM}$ in each case). Human MPs plated on 24 -well plates $\left(\sim 10^{5}\right.$ cells/well $)$ were transferred to the hypoxia chamber followed by the exchange of the medium with RPMI 1640 containing human serum $(0.5 \%)$, and then incubated for $24 \mathrm{~h}$ in the presence or absence of the antisense oligonucleotides. The selectivity of the antisense for suppressing expression of ORP150 was confirmed by performing two lines of experiments: comparing their effect (antisense and sense, BK-60') on induction of HSP72 (3), and evaluating the effect of the sense oligonucleotide $\left(\mathrm{BK}-60^{\prime}\right)$ on the induction of ORP150 by hypoxia.

Where indicated, MP cultures were exposed to hypoxia for $24 \mathrm{~h}$ in the presence of either antisense or sense oligonucleotides $(20 \mu \mathrm{M}$ in both cases) and then Ox-LDL (50 $\mu \mathrm{g} / \mathrm{ml})$ was added to the culture $8 \mathrm{~h}$ before harvest. Viability of MPs was assessed by measuring the release of LDH activity (Sigma Chemical Co.) into the culture supernatant at the end of the experiment. Where indicated, either probucol $(10 \mu \mathrm{M})$ or $N$-acetylcysteine $(10 \mathrm{mM}$, both reagents were from Sigma Chemical Co.) was added to the culture at the beginning of hypoxia.

Detection of human endogenous antibody to ORP150 in the serum of patients with severe atherosclerosis. The existence of endogenous anti-ORP150 antibody in the serum of patients with severe atherosclerosis was evaluated by immunoblotting using patient serum. Protein extract of human MPs (corresponding to $\sim 5 \mu \mathrm{g}$ protein) exposed to hypoxia $(24 \mathrm{~h})$ was subjected to SDS-PAGE $(10 \%)$, transferred to polyvinylidene difluoride paper, and reacted with test serum (1:50 dilution) obtained from patients with severe atherosclerosis (see Results for definition of this patient group) or healthy agematched volunteers. To confirm that patient serum specifically reacted with human ORP150, membranes with immobilized extract of hypoxic MPs were pretreated with excess rabbit anti-rat ORP150 antibody. The membranes were then washed and stained with goat antihuman IgG (Organon-Teknika, West Chester, PA) as described above.

To better compare the level of anti-ORP150 autoantibody in patient sera, an ELISA was developed as described previously (26) using fractions from hypoxic U373 cells. In brief, U373 cells $\left(\sim 10^{8}\right.$ cells) were exposed to hypoxia for $48 \mathrm{~h}$ and ORP150 was partially purified by ion exchange chromatography on fast protein liquid chromatography Mono Q as described (5). The ORP150-enriched fraction ( $\sim 20 \mu \mathrm{g}$ protein) was then absorbed onto microtiter wells of ELISA plates to which rabbit anti-human ORP150 IgG $(\sim 5 \mu \mathrm{g}$; derived from immunizing rabbits with ORP150-derived peptides; see above) had already been bound. After incubation at $37^{\circ} \mathrm{C}$ for $1 \mathrm{~h}$, plates were washed three times with PBS containing Tween-20 (0.05\%) and incubated for $1 \mathrm{~h}$ at $37^{\circ} \mathrm{C}$ with patients' serum at indicated dilution in PBS with Tween-20 $(0.05 \%)$ and casein $(0.1 \%)$. Plates were then washed four times with PBS containing Tween $20(0.05 \%)$, sites of primary antibody were visualized after addition of peroxidase-conjugated anti-human IgG (Boehringer Mannheim) and $\mathrm{OD}_{495}$ was measured by Titerteck (Dainippon Co., Japan). Background $\mathrm{OD}_{520}$ in each serum was obtained by preincubating anti-rat ORP150 $\operatorname{IgG}(10 \mu \mathrm{g}$ in each well) $1 \mathrm{~h}$ at $37^{\circ} \mathrm{C}$ before the addition of patient serum. AntiORP150 autoantibody in patient serum was titrated by the diluting until $\mathrm{OD}_{495}=0.2$ was obtained.

Statistical analyses were performed by either Newman-Keul's method for the multiple comparisons, employing analysis of variance, or nonpaired $t$ test, as indicated.

\section{Results}

Expression of ORP150 antigen and message in cultured vascular cells. Exposure of cultured HeLa cells (Fig. $1 A$ ), the human glioma cell line U373 (Fig. $1 A$ ), MPs (Fig. $1 C$ ), and aortic SMCs (Fig. $1 D$ ) to hypoxia resulted in expression of the 150-kD ORP based on immunoblotting of cell lysates with antibody raised to a peptide derived from the sequence of human ORP150. The specificity of the $150-\mathrm{kD}$ band observed with anti-human ORP150-derived peptide IgG for ORP150 was confirmed by absence of an immunoreactive band when lysate of hypoxic U373 cells was preadsorbed with rabbit antibody raised to purified rat ORP150 (Fig. $1 \mathrm{~B}$, ORP150; note that rat ORP150 shows about $90 \%$ homology to human ORP150). In contrast, pretreatment of hypoxic cell lysates with nonimmune IgG had no effect on detection of the $150-\mathrm{kD}$ band based on immunoblotting with anti-ORP150-derived peptide antiserum (Fig. $1 \mathrm{~B}$, nonimmune). Time course experiments in MPs and SMCs showed increased expression of the ORP150 antigen within 12 and $24 \mathrm{~h}$ of hypoxia, and diminished expression by $24 \mathrm{~h}$ 
A

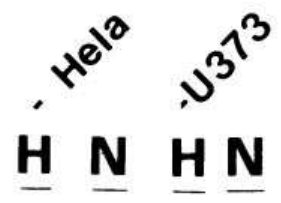

200-

116-

97.4-

66-

46-

C MPs

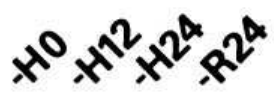

200-

116-

97.4-

66-

46-
B

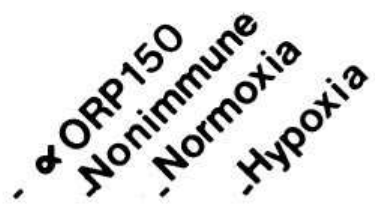

200-

$116-$

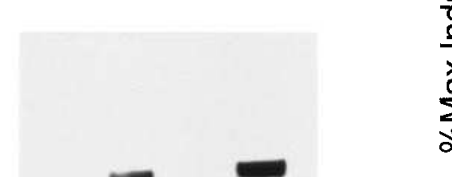

97.4-

66-

46-

D SMCs
E

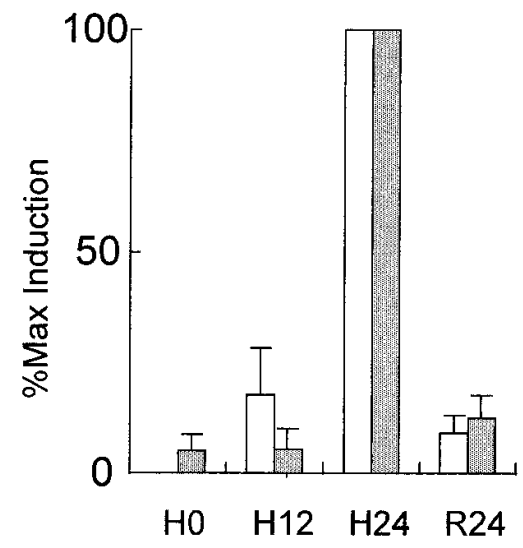

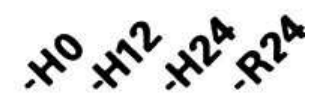

200-

$116-$

97.4-

66-

46-

Figure 1. Expression of ORP150 antigen in cultured human cells exposed to hypoxia and specificity of the anti-human ORP150 antibody and cultured human vascular cells. $(A)$ HeLa or U373 cells (human glioma cell line) were cultured and exposed to hypoxia $(H)$ or normoxia $(N)$ for $24 \mathrm{~h}$. Cell extracts ( $3 \mu \mathrm{g}$ protein each) were subjected to SDS-PAGE $(7.5 \%)$ and immunoblotting. Immunoreactive protein was visualized by reacting blots with anti-human ORP150 antibody followed by secondary antibody. $(B)$ Lysate of hypoxic U373 cells $\left(5 \times 10^{8}\right.$ cells $)$ was preadsorbed with either anti-ORP150 IgG raised against purified rat ORP150 ( $\alpha$ ORP150) or nonimmune IgG (Nonimmune) and protein A was added. IgG-protein A complexes were collected by centrifugation, supernatant was concentrated (to $\sim 20 \mu l$ in each case) and subjected to reduced SDS-PAGE $(7.5 \%)$ followed by immunoblotting. Other samples applied to the gel were lysate of normoxic (Normoxia) or hypoxic (Hypoxia) U373 cells ( $\sim 3 \mu \mathrm{g}$ protein) without further processing. After Western blotting, membranes were reacted with anti-ORP150 IgG (5 $\mu \mathrm{g} /$ $\mathrm{ml}$ ) raised against the peptide synthesized to the $\mathrm{NH}_{2}$-terminal sequence of human ORP150. ( $C$ and $D$ ) Human peripheral blood-derived mononuclear phagocytes (MPs, $C$ ) or vascular smooth muscle cells (SMCs, $D$ ) were plated in 10 -cm dishes $\left(10^{6}\right.$ cells in each case) and exposed to hypoxia alone for the indicated times $(H 0,0 \mathrm{~h} ; H 12,12 \mathrm{~h}$; and $H 24,24 \mathrm{~h})$, or hypoxia $(24 \mathrm{~h})$ followed by reoxygenation $(R 24,24 \mathrm{~h})$. At the indi- 


\section{Normoxia

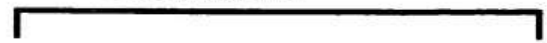 \\ N H Na Ac Ox LP IN 2D HTHPCo}
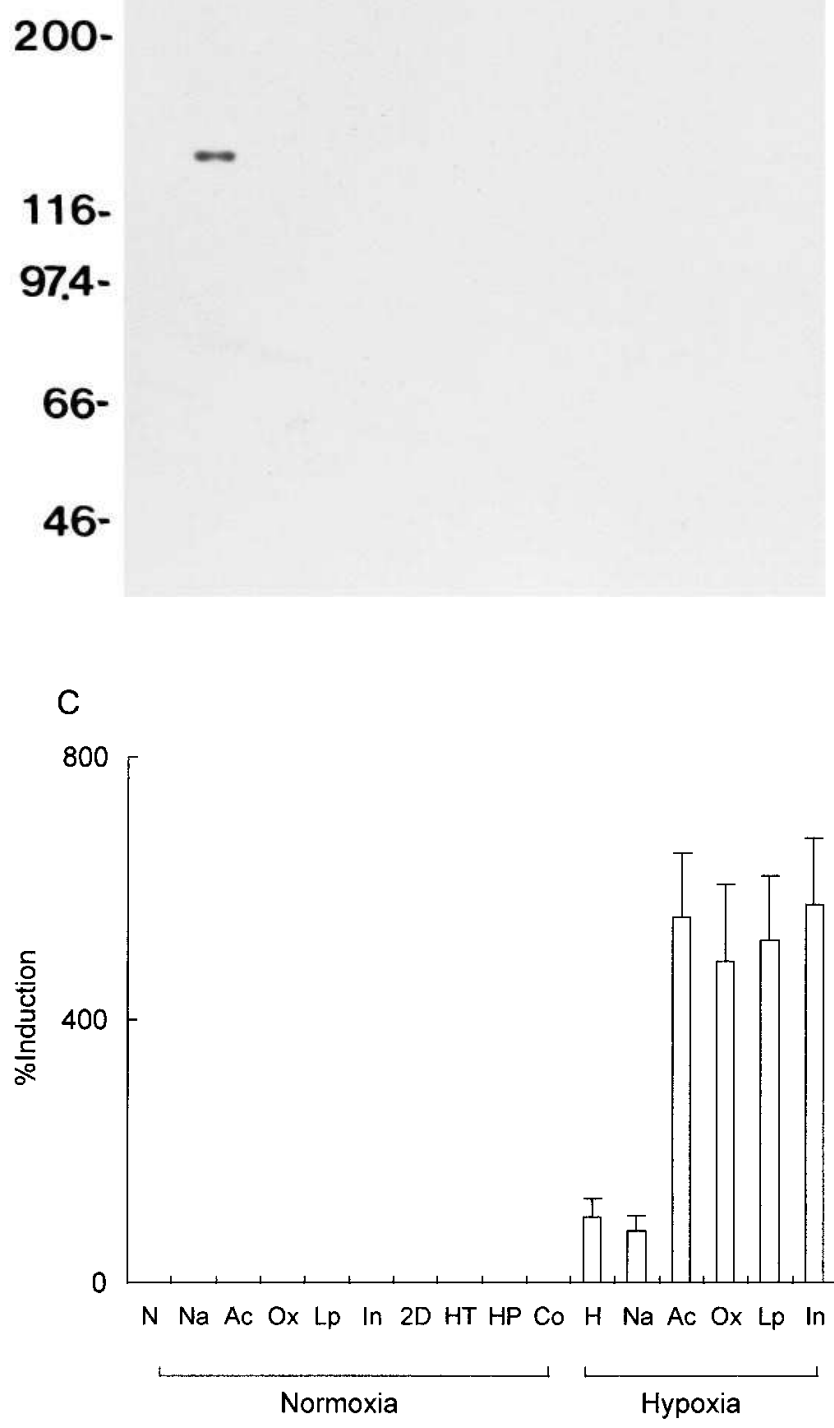

after replacement in normoxia or reoxygenation (Fig. 1, $C$ and $D$, respectively). More detailed studies in MPs demonstrated that hypoxia was unique in eliciting expression of ORP150 compared with multiple other stimuli, including hydrogen peroxide, 2-deoxyglucose, oxidized/acetylated LDLs,

\section{Hypoxia \\ $\longrightarrow$ \\ N H Na Ac Ox LP IN}

200-

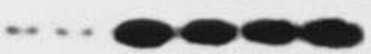

116-

974-

66-

46-

Figure 2. Induction of ORP150 antigen in cultured human peripheral blood-derived MPs under normoxic $(A)$, hypoxic $(B)$ conditions, and laser densitometric analysis $(C)$. Effect of modified LDL, lipopolysaccharide $(L P), \gamma$-interferon $(I N), 2$-deoxyglucose $(2 D)$, heat shock $(H T)$, hydrogen peroxide $(H P)$, and cobalt $(C o)$. ( $A$ and $B)$ MPs were plated in $10-\mathrm{cm}$ dishes $\left(10^{6}\right.$ cells in each case $)$ and exposed to either normoxia $(N)$ or hypoxia $(H)$ alone for $24 \mathrm{~h}$, or in the same environment (normoxia or hypoxia) in the presence of one of the following added $8 \mathrm{~h}$ before harvesting of cells: native LDL $(N a, 50 \mu \mathrm{g} / \mathrm{ml})$, acetylated LDL $(A c, 50 \mu \mathrm{g} / \mathrm{ml})$, oxidized LDL (Ox, $50 \mu \mathrm{g} / \mathrm{ml})$, lipopolysaccharide $(L P, 10 \mu \mathrm{g} / \mathrm{ml})$, or $\gamma$-interferon (IN, $5 \mathrm{ng} / \mathrm{ml}$ ). MPs in normoxia were also subjected to either heat shock $\left(43^{\circ} \mathrm{C}\right.$ for $\left.3 \mathrm{~h}, H T\right)$, exposure to hydrogen peroxide $(5 \mu \mathrm{M}$ for $10 \mathrm{~min}$, $H P)$ followed by a 6-h incubation period, 2-deoxyglucose $(25 \mathrm{mM}$, $2 \mathrm{D})$ or cobalt chloride $(1 \mathrm{mM}, \mathrm{Co})$ for $24 \mathrm{~h}$. Cells were then harvested as described in Fig. 1, and $5 \mu \mathrm{g}$ from each sample were subjected to immunoblotting using the same antibody preparations. The migration of simultaneously run molecular weight markers is shown on the left side of the gel. (C) Induction of ORP150 in MPs obtained from six different donors was quantified by the laser densitometric analysis. Values are expressed as percent induction of that observed in MPs exposed to hypoxia alone. Mean \pm SD is shown. These experiments were repeated a minimum of three times.

LPS, $\gamma$-interferon, or heat shock (Fig. 2, $A$ and $C$ ). In contrast, the combination of hypoxia in concert with these other factors, such as modified LDLs, LPS, and $\gamma$-interferon, greatly potentiated induction of ORP150 antigen ( $>$ sevenfold by densitometry) compared with hypoxia alone (Fig. 2, $B$ and $C$ ). Substitu-

cated times, cells were harvested as above, and each sample $(3 \mu \mathrm{g})$ was subjected to immunoblotting using anti-ORP150 IgG. The migration of simultaneously run molecular weight markers is indicated on the left side of the gel (ovalbumin [46 kD], bovine serum albumin [66 kD], phosphorylase b [97.4 kD], $\beta$-galactosidase [116 kD], and myosin [200 kD]). (E) Laser densitometric analysis of Western blots of mononuclear phagocytes (open column) derived from six different donors and human aortic SMCs (closed column) derived from three different donors. The densitometric value of each band was expressed as the percentage of maximal induction of ORP150 in each cell type. Mean \pm SD is shown. These experiments were repeated a minimum of four times. 


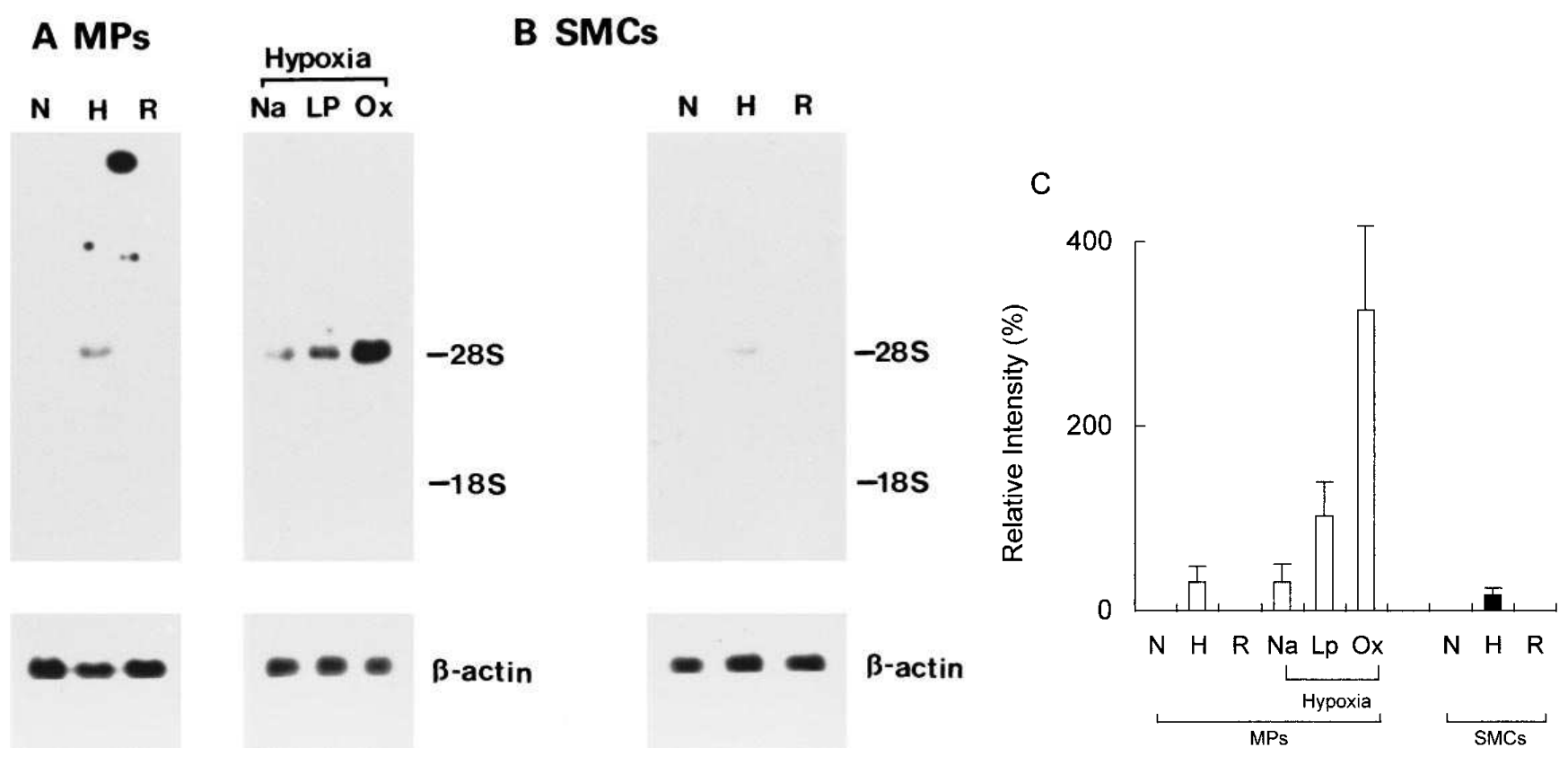

Figure 3. Induction of ORP150 transcripts in cultured human MPs and vascular SMCs. Either human MPs $(A)$ or SMCs $(B)\left(\sim 10^{8}\right.$ cells in each case) were exposed to normoxia $(N)$ or hypoxia alone for $24 \mathrm{~h}(H)$, or hypoxia followed by reoxygenation for $24 \mathrm{~h}(R)$. MPs were also incubated under hypoxic conditions $(24 \mathrm{~h})$ in the presence of either native LDL $(N a, 50 \mu \mathrm{g} / \mathrm{ml})$ or oxidized LDL $(O x, 50 \mu \mathrm{g} / \mathrm{ml})$, or lipopolysaccharide $(L P$, $10 \mu \mathrm{g} / \mathrm{ml}$ ) added for the $8 \mathrm{~h}$ before harvest. RNA was extracted, subjected to agarose (1\%) gel electrophoresis, transferred to nylon membranes, and hybridized to a radiolabeled rat ORP150 cDNA probe. The membrane was dried and subjected to autoradiography. Samples were also hybridized with radiolabeled human $\beta$-actin probe as shown in the lower panels. The migration of ribosomal RNA bands is indicated in the right side of the gel. (C) Expression of ORP150 transcripts in MPs (open bars) obtained from four different donors and SMCs (closed bar) from three different donors was standardized by laser densitometric analysis. Values are expressed by relative intensity compared with that of $\beta$-actin. Mean $\pm \mathrm{SD}$ is shown. These experiments were repeated a minimum of four times.

tion of native LDL for oxidized/acetylated LDLs resulted in no enhancement of ORP150 expression (Fig. 2, $B$ and $C$ ). The enhancement of ORP150 in MPs' expression by the combination of hypoxia and the latter stimuli was not observed in cultured human SMCs under the same conditions (data not shown). Experiments with human MPs employed cells from a total of 10 donors (6 donors for Western analysis as in Fig. $1 C$, and 4 donors for Northern analysis as in Fig. $3 A$, see below). With cells from each donor, hypoxia enhanced ORP150 induction, although the absolute level of increased ORP150 expression varied somewhat from donor to donor.

Expression of ORP150 antigen was preceded by an increase in transcripts in both MPs and SMCs, compared with virtually undetectable mRNA levels in normoxic cultures or hypoxic cultures incubated in normoxia for $24 \mathrm{~h}$ (Fig. 3, $A-C$ ). The band to which the rat cDNA for ORP150 hybridized in RNA extracted from these human cell types displayed similar migration to the $4.2 \mathrm{~kb}$ corresponding to the size of the fulllength cDNA for human ORP150. At the mRNA level, hypoxia + either oxidized LDL or lipopolysaccharide appeared to augment the level of transcripts in MPs compared with hypoxia alone (no band was evident in samples from cultures exposed to oxidized LDL under normoxic condition, data not shown). Native LDL at the same concentration had no effect on the level of ORP150 mRNA (Fig. $3 A$ ).

Expression of ORP150 antigen and message in human vascular tissue. These data suggested that the presence of modified lipoproteins might promote ORP150 induction, leading us to assess its expression in human aortae. Anti-human
ORP150-derived peptide antibody visualized a single band with $M_{\mathrm{r}} \sim 150 \mathrm{kD}$ in the samples from segments of aorta with severe atherosclerosis. In contrast, slight or no corresponding band was detectable in the tissue extract obtained from aortae without atherosclerotic changes beyond early lesions (Fig. 4, $A$ and $C$ ). Northern analysis showed marked induction of ORP150 mRNA in samples from severe atherosclerotic lesions (Fig. 4, $B$ and $C$ ). In contrast, slight or no ORP150 message was detected in RNA harvested from portions of aorta with or without only minimal atherosclerosis, or in apparently normal aortic tissue from younger individuals (Fig. 4, $B$ and $C$ ). These data suggest that ORP150 is selectively induced in severe atherosclerotic lesions of human aorta.

To further assess the localization of ORP150 message in atherosclerotic lesions, in situ hybridization using rat ORP150 riboprobes was undertaken. In aortic samples, ORP150 transcripts were detected in neointima and close to atheromatous debris (Fig. 5, $A, C$, and $E$ ) of an atherosclerotic lesion in thoracic aorta (Fig. $5 B$ shows hematoxylin and eosin staining of an adjacent section to $A$ for orientation). When sections were hybridized with sense probe in place of antisense probe, no significant staining was observed. Other controls, in which samples were pretreated with RNase or either the antisense riboprobe or antibody to digoxigenin was omitted, similarly showed no staining (data not shown). Adjacent sections stained with antibodies to the smooth muscle cell $\alpha$-actin (Fig. $5 \mathrm{D}$ ) and the macrophage marker CD68 (Fig. $5 F$ ) indicated that the predominant cells colocalized with ORP150 mRNA were macrophages. Additional studies in sections of athero- 
N H $12 \begin{array}{lllll} & 3 & 4 & 5 & 6\end{array}$

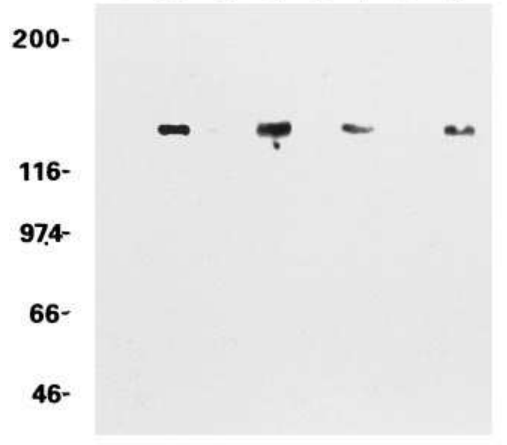

$\begin{array}{lllllllll}1 & 2 & 3 & 4 & 5 & 6 & 7 & 8\end{array}$

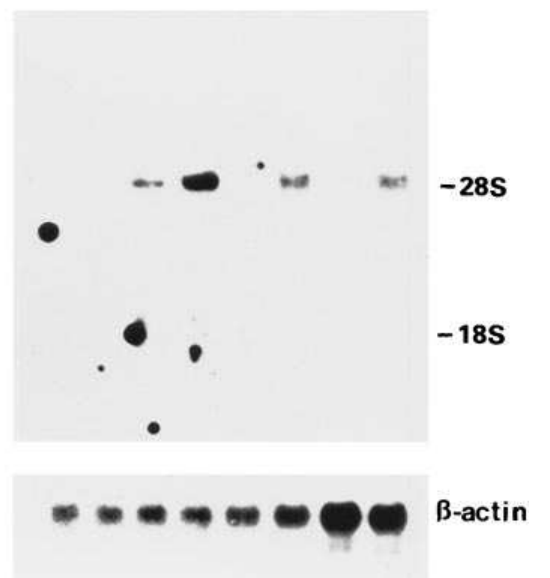

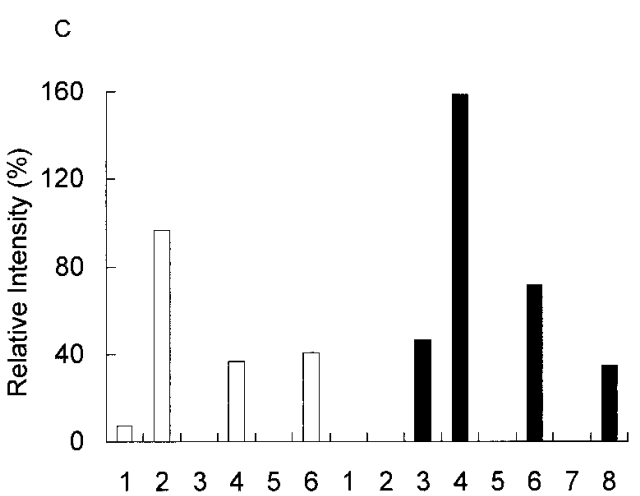

Figure 4. Expression of ORP150 antigen $(A)$, mRNA $(B)$ in human aorta, and laser densitometric analysis of both blots $(C)$. $(A)$ Protein was extracted from human aorta after acetone precipitation in PBS containing NP-40 (1\%). The concentration of protein (based on total protein and the content of SMC $\alpha$-actin, see text) in samples was adjusted to be equivalent, and samples were subjected to immunoblotting using anti-human ORP150 antibody. Lanes represent samples obtained from normoxic astrocytes $(N)$, hypoxic astrocytes $(H)$, early $(1,3,5)$, and advanced lesions $(2,4,6)$ from three patients: case A, a 65-yr-old female who died of sepsis after operation for dissecting aneurysm $(1$ and 2$)$; case B, a 65 -yr-old male who died of rupture of dissecting aneurysm ( 3 and 4$)$; and case C, a 71-yr-old male who died of cerebral infarction (5 and 6$)$. The migration of simultaneously run molecular weight markers is shown on the left side of the gel. (B) Total RNA (10 $\mu \mathrm{g} / \mathrm{lane})$ purified from human aortae was subjected to Northern analysis using either radiolabeled rat ORP150 probe (top) or $\beta$-actin probe (bottom). RNA for lane 1 was obtained from the aorta of a 1-yr-old boy who died of congenital heart disease, and that for lane 2 from a 9 -yr-old boy who died of chondrosarcoma. RNA for lanes 3 and 4 was from the same samples as in lanes 1 and 2 in $A$. RNA for lanes 5 and 6 was from early and advanced aortic lesions, respectively, of a 77-yr-old male who died of cardiac rupture after acute myocardial infarction. RNA from lanes 7 and 8 was from early and advanced lesions, respectively, of an 83-yr-old male who died of cerebral infarction. The migration of ribosomal RNA is indicated on the right side of the gel. $(C)$ The content of ORP150 antigen (open bars) and transcripts (closed bars) is represented by the percent ratio to that of $\alpha$-actin for ORP150 antigen and $\beta$-actin for ORP150 transcripts, respectively.

sclerotic coronary arteries in which few infiltrating macrophages were present demonstrated the presence of ORP150 mRNA (Fig. 6, $B$ and $E$ ) in a subpopulation of SMCs (Fig. 6, $C$ and $F$, these panels demonstrate anti-smooth muscle $\alpha$-actin staining of sections adjacent to $B$ and $E$, respectively; Fig. 6, $A$ and $D$ show hematoxylin and eosin staining of adjacent sections to $B$ and $E$, respectively, for orientation). Comparing SMC and MP expression of ORP150 in these atherosclerotic lesions suggested that MP production of ORP150 was strongly inducible, probably as a result of the microenvironment of the atherosclerotic plaque.

Effect of ORP150 antisense nucleotides on the viability of MPs subjected to hypoxia. To understand functional effects of ORP150 in hypoxic mononuclear phagocytes, studies were performed using three antisense constructs corresponding to regions around the initiation codon of human ORP150 (Fig. $7 A$ ). Of these, BK-60 most effectively suppressed induction of ORP150, as was found previously when these antisense constructs were employed in cultured astrocytes (25). MPs exposed to hypoxia expressed ORP150 (Fig. $7 \mathrm{~B}$, lane 2), which was suppressed to virtually undetectable levels on addition of BK-60 (Fig. $7 \mathrm{~B}$, lane 3), comparable to what was observed in normoxic MPs (Fig. $7 \mathrm{~B}$, lane 1 ). In contrast, the corresponding sense oligonucleotide (BK-60') had no effect on ORP150 expression in hypoxic MPs (Fig. $7 \mathrm{~B}$, lane 4 ). The specificity of the effects of BK-60 for suppression of ORP150 expression were confirmed by experiments demonstrating its lack of effect on induction of HSP72 after exposure of MPs to heat shock (Fig. $7 \mathrm{~B}$, lanes 6 and 7 ; note that lane 5 shows control MPs not exposed to heat shock and lane 8 shows hypoxic MPs exposed to the sense oligonucleotide).

A functional role for ORP150 in the adaptation of cultured MPs to hypoxia was suggested by the impairment of cell viability in cultures subject to oxygen deprivation, especially in the presence of oxidized LDL. Although MPs exposed to hypoxia for $24 \mathrm{~h}$ showed no significant release of LDH into the medium, when BK-60 was added to suppress ORP150 expression, cell viability was diminished to a small, but significant extent. Addition of oxidized LDL to the medium of hypoxic MPs incubated with BK-60 markedly diminished cell viability compared with cultures in which ORP150 expression was not suppressed (Fig. $7 \mathrm{C}$ ). Addition of Ac-LDL diminished viability of MPs in a manner analogous to Ox-LDL (data not shown). In contrast, native LDL did not affect the viability of hypoxic MPs, even in the presence of antisense oligonucleotide (Fig. $7 \mathrm{D}$ ).

To further assess mechanisms through which ORP150 exerted its cytoprotective effect in hypoxic MPs incubated with oxidized LDL, we evaluated the effect of antioxidants, probucol, and $N$-acetylcysteine. Cultures in which ORP150 expression was suppressed by the antisense oligonucleotide (BK-60) 

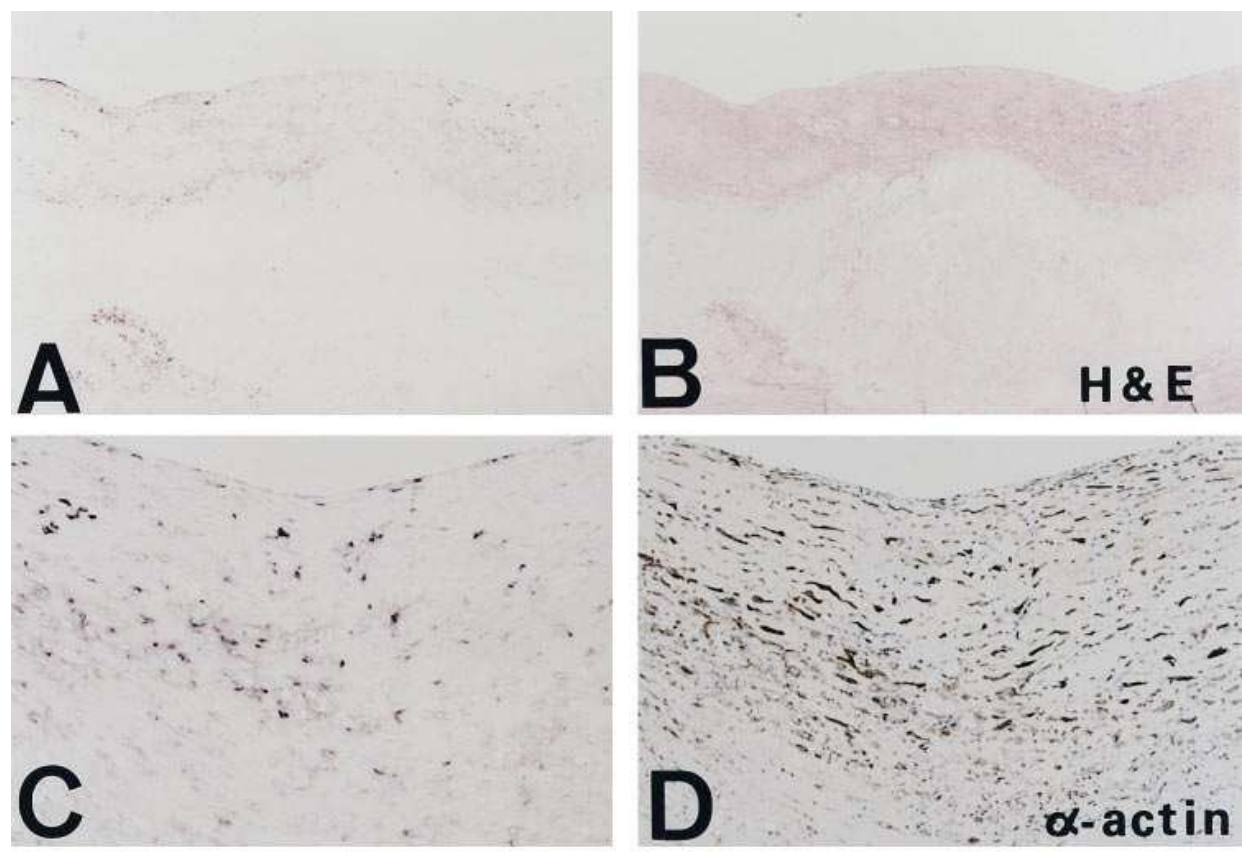

Figure 5. Localization of ORP150 mRNA in atheromatous plaque of aorta. Thoracic aorta was prepared from the 77-yr-old male who died of cardiac rupture after acute myocardial infarction (Fig. $4 B$, lanes 5 and
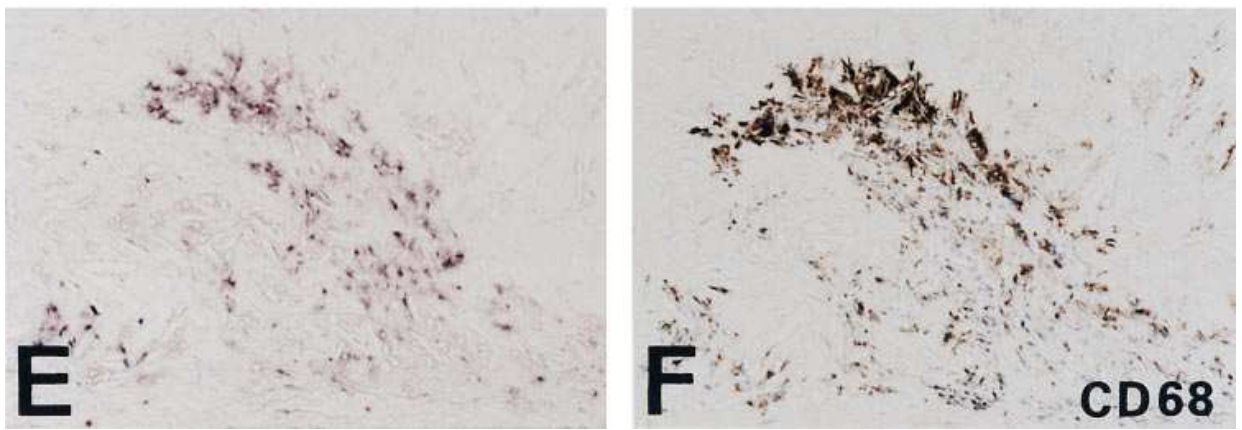

6 ) within $3 \mathrm{~h}$ of death and fixed with $4 \%$ paraformaldehyde in $0.1 \mathrm{M}$ phosphate buffer, $\mathrm{pH}$ 7.0. Tissue specimens were subjected to in situ hybridization using rat ORP150 probe ( $A, 20 \times ; C$ and $E, 80 \times$ ). Adjacent sections were stained with hematoxylin and eosin $(B, 20 \times)$, monoclonal antibody $1 \mathrm{~A} 4(D, 80 \times)$, or monoclonal antibody PG-M1 (anti-CD68 $\mathrm{IgG} ; F, 80 \times)$.

were exposed to hypoxia and oxidized LDL (50 $\mu \mathrm{g} / \mathrm{ml})$; both probucol and $\mathrm{N}$-acetylcysteine had strong protective effects (Fig. 7 E).

The presence of anti-ORP150 antibody in plasma of patients with severe atherosclerosis. In view of the association of ORP150 expression with cellular stress, as in severe athero- sclerosis, we speculated that patients with extensive vascular disease might develop autoantibodies. Western blotting was performed using cell lysates from cultured human MPs exposed to hypoxia as the source of ORP150, and patient sera at 1:50 dilution (Fig. 8). Sera from two patients with angiographically demonstrated severe atherosclerotic vascular disease of

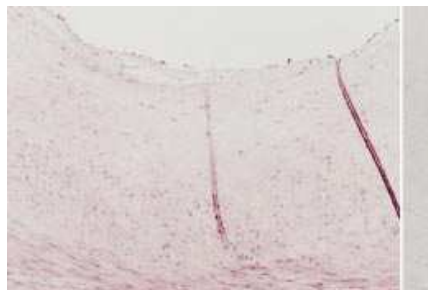

A

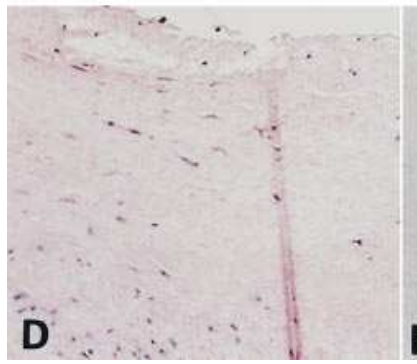

B

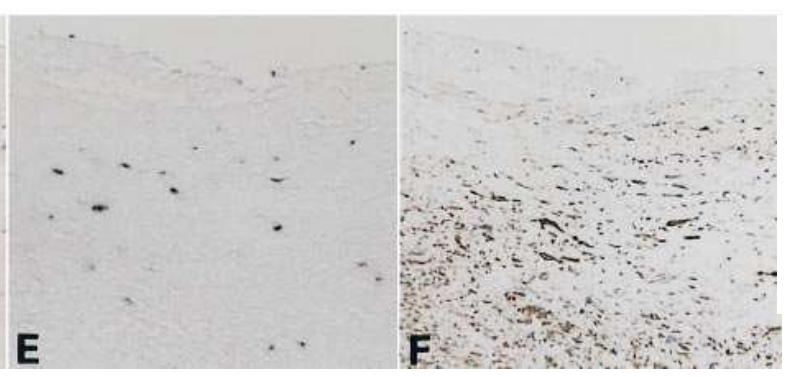

Figure 6. Localization of ORP150 mRNA in coronary artery. Coronary artery was obtained from the 83-yr-old male who died of cerebral infarction (Fig. $4 B$, lanes 7 and 8 ), and subjected to in situ hybridization using rat ORP150 probe $(B, 40 \times$ and $E, 100 \times)$. Adjacent sections were stained with hematoxylin and eosin $(A$, $40 \times$ and $D, 100 \times)$ or $1 \mathrm{~A} 4(C, 40 \times$ and $F$, $100 \times)$. 

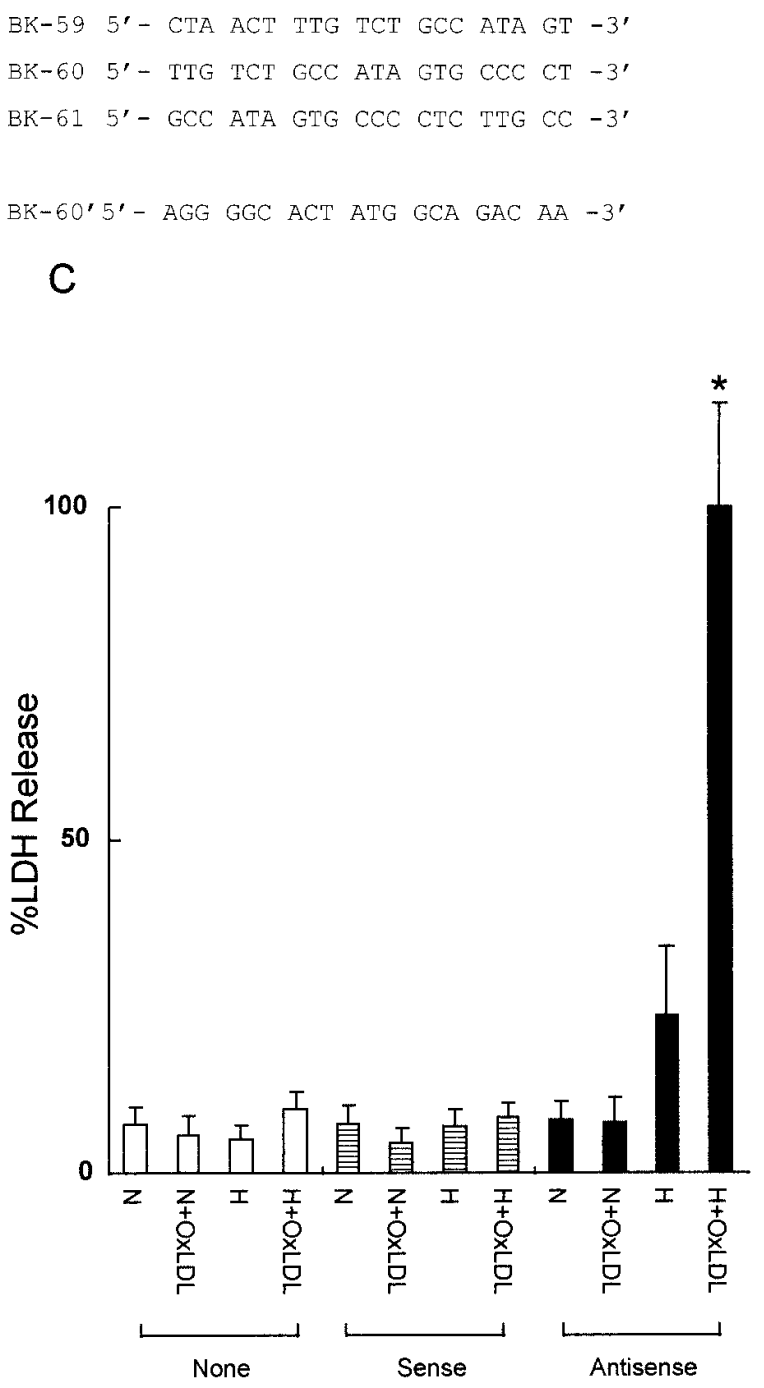

ORP150

\section{4}

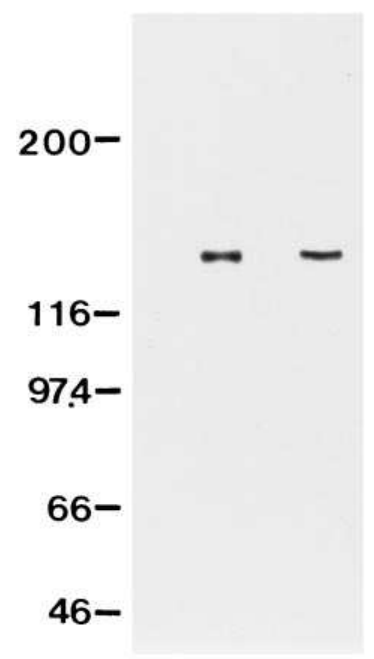

HSP72

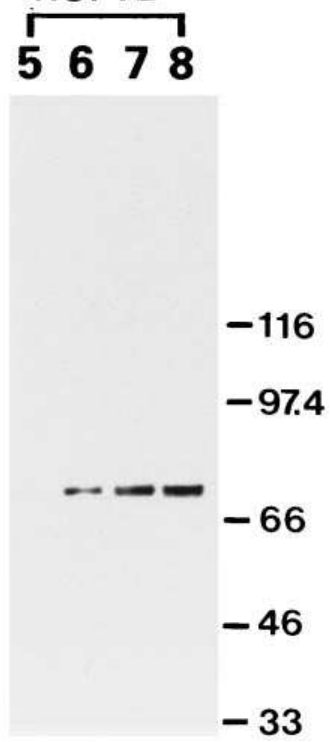

Figure 7. Effect of ORP150 antisense oligonucleotide BK-60 on the induction of stress proteins and viability of MPs in hypoxia. (A) Schematic depiction of ORP150 antisense (BK-59, 60, 61) and sense (BK-60') oligonucleotides. $(B)$ Human MPs $\left(\sim 10^{6}\right.$ cells $)$ were cultured and exposed to hypoxia for $24 \mathrm{~h}$ either in the absence (lane 2) or presence of ORP150 antisense (BK-60, $20 \mu \mathrm{M}$, lane 3) or the sense oligonucleotide (BK-60', 20 $\mu \mathrm{M}$, lane 4). Cells were harvested and $3 \mu \mathrm{g}$ protein was subjected to immunoblotting using anti-ORP150 IgG as described (lanes 1-4). Normoxic control sample is shown in lane 1. For detection of HSP72 (lanes 5-8), cultured MPs were exposed to elevated temperature $\left(43^{\circ} \mathrm{C}\right)$ for $3 \mathrm{~h}$ in the absence (lane 6) or presence of ORP150 antisense (BK-60, $20 \mu \mathrm{M}$, lane 7) or sense oligonucleotide (BK-60', $20 \mu \mathrm{M}$, lane 8 ). Protein was extracted from each sample $(\sim 3 \mu \mathrm{g})$ and subjected to immunoblotting with anti-HSP72 antibody. A control experiment was also performed with MPs without exposure to elevated temperature (lane 5). The migration of simultaneously run molecular weight markers is shown on both sides of the gel. (C) Human MPs $\left(\sim 2 \times 10^{5}\right.$ cells $)$ were cultured under either normoxic $(N)$ or hypoxic $(H)$ condition for $24 \mathrm{~h}$ either in the absence (open bars) or presence of sense oligonucleotide (BK- $60^{\prime}, 20 \mu \mathrm{M}$, hatched bars) or antisense oligonucleotide (BK- $60,20 \mu \mathrm{M}$, closed bars). Where indicated, oxidized LDL $(50 \mu \mathrm{g} / \mathrm{ml})$ was added to the culture $8 \mathrm{~h}$ before harvest $(O x L D L)$. LDH activity in the culture supernatant was then measured and expressed as a percentage of maximal release (arbitrarily defined as $100 \%$ in the presence of hypoxia + oxidized LDL + BK- 60 ). Mean \pm SD is shown $(n=6)$. ${ }^{*} P<0.01$ by Newman-Keul's analysis compared with $\mathrm{H}$ in the presence of BK-60. $(D)$ Human MPs $\left(\sim 2 \times 10^{5}\right.$ cells $)$ were cultured under hypoxic $(H)$ conditions for $24 \mathrm{~h}$ either in the absence (open bars) or presence of sense oligonucleotide $\left(\mathrm{BK}-60^{\prime}, 20 \mu \mathrm{M}\right.$, hatched bars) or antisense oligonucleotide (BK-60, $20 \mu \mathrm{M}$, closed bars). Either oxidized LDL (OxLDL, 50 $\mu \mathrm{g} / \mathrm{ml})$ or native LDL (NaLDL, $50 \mu \mathrm{g} / \mathrm{ml})$ was added to the culture $8 \mathrm{~h}$ before harvest. LDH activity in each culture was measured and expressed as a percentage of maximal release (that observed in cultures exposed to hypoxia + oxidized LDL + BK-60 assigned a value of $100 \%)$. $* * P<0.01$ compared with $\mathrm{H}+\mathrm{NaLDL}+\mathrm{BK}-60$ by nonpaired $t$ test. $(E)$ Human MPs $\left(\sim 2 \times 10^{5}\right.$ cells) were cultured for $24 \mathrm{~h}$ under hypoxia in the presence (closed bars) or absence (open bars) of antisense oligonucleotide (BK-60, $20 \mathrm{mM})$. Oxidized LDL $(50 \mu \mathrm{g} / \mathrm{ml})$ was added to each culture $8 \mathrm{~h}$ before harvest. Where indicated, either probucol $(10 \mu \mathrm{M} ; \mathrm{Pb})$ or $N$-acetylcysteine $(10 \mathrm{mM} ; N A C)$ was added to the culture $30 \mathrm{~min}$ before addition of oxidized LDL. LDH activity in each culture was measured and expressed as a percentage of maximal release (that observed in cultures exposed to hypoxia + oxidized LDL + BK-60 assigned a value of $100 \%$ ). The arbitrarily defined $100 \%$ point for loss of cell viability used in panels $C-E$ corresponds to the release of $85 \%$ of the LDH activity observed when a freeze-thaw lysate of the cell preparations was made. ${ }^{* *} P<0.05$ by Newman-Keul's analysis compared with $\mathrm{H}$ in the presence of BK-60. In each case, experiments were repeated a minimum of four times. 


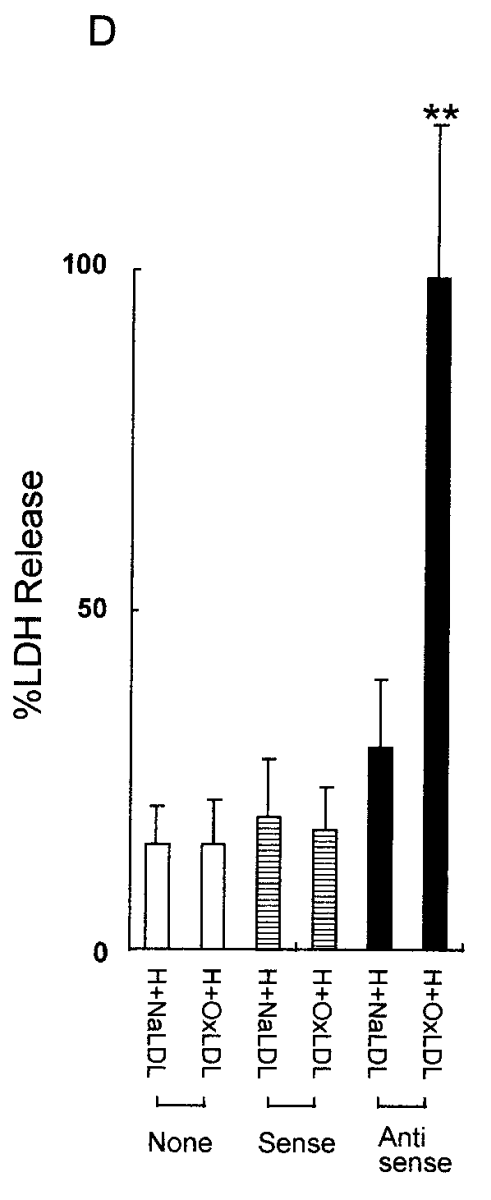

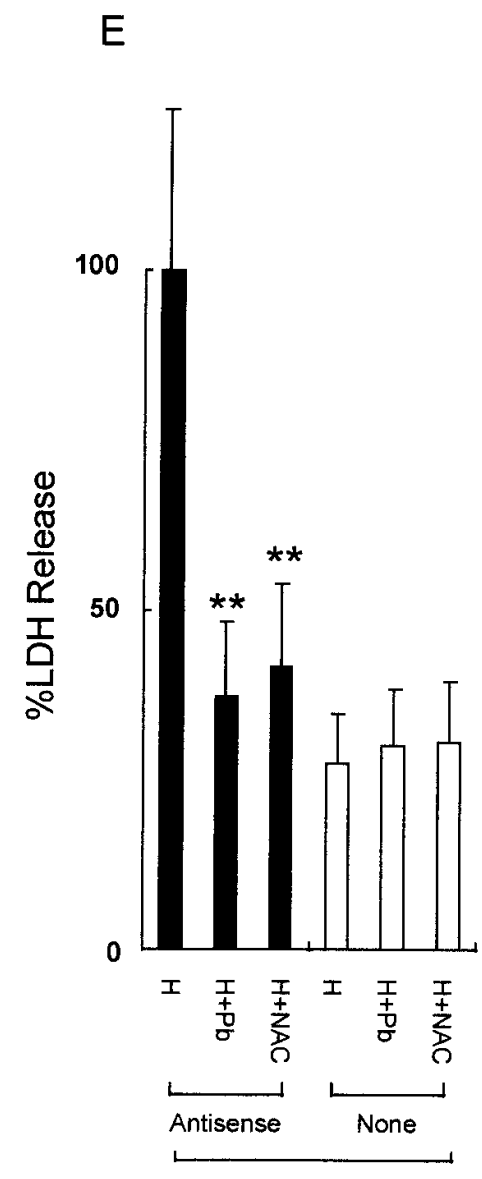

Hypoxia+OXLDL
Figure 7. the thoracic and abdominal aorta were studied. Patient A was a 73-yr-old male with angina pectoris who also suffered from occlusion of the right common carotid artery, and patient B was a 65 -yr-old male whose vascular disease included subcomplete stenosis of both carotid arteries. Sera from patients A and $\mathrm{B}$ detected the 150-kD band in hypoxic MPs (Fig. 8, lanes 3 and 5), and appearance of the band was blocked by addition of excess of anti-human ORP150 antibody (Fig. 8, lanes 4 and 6). Sera from an age-matched control individual with no evident vascular disease showed no immunoreactivity with the 150-kD band (Fig. 8, lanes 7 and 8). We developed an ELISA to facilitate comparison of anti-ORP150 antibodies in patient sera, and used this method to analyze additional patient samples (Table I). The results in the ORP150 ELISA confirmed the presence of significant titers of autoantibodies in four of six patients with advanced atherosclerosis, whereas none of the age-matched controls (i.e., patients without evidence of atherosclerotic complications) had significant titers. It is important to note that sera from patients with atherosclerosis were also reactive with other polypeptides whose expression was induced in MPs by oxygen deprivation, especially those with $M_{\mathrm{r}} \mathrm{s}$ corresponding to $\sim 72$ and $98 \mathrm{kD}$.

\section{Discussion}

Chronic and intermittent hypoperfusion in arterial wall, resulting in insufficient delivery of nutrients to vascular cells, is believed to contribute to the pathogenesis of atherosclerotic le- sions (27-30). One important facet of this ischemic milieu is oxygen deprivation in the vascular microenvironment (31). In this context, experimental atherosclerosis and hypertension are associated with diminished arterial wall oxygenation $(32,33)$, suggesting that relative hypoxia of vascular cells may be a common event in vascular dysfunction.

ORP150, originally purified and cloned from cultured rat astrocytes exposed to hypoxia, has also been observed in certain tumor cells subject to oxygen deprivation (34). A principal factor underlying ORP150 induction is lowering of ambient oxygen tension in a range of cell types (HeLa, U373, MPs, and smooth muscle cells). Among cells of the atherosclerotic vessel wall, MPs appear to express the highest levels of ORP150. This is consistent with our results in cell culture demonstrating increased expression of ORP150 by MPs, which is further potentiated in the presence of pathophysiologically relevant perturbants such as modified LDL. The observed elevated levels of ORP150 mRNA in MPs present in atherosclerotic plaques emphasize the association of ORP150 with cellular stress, although it is likely that more complex mechanisms may contribute to ORP150 expression in late atherosclerotic lesions compared with those operative in vitro. Previous studies have shown that a range of other stress proteins are induced by hypoxic and/or ischemic stress, (e.g., glucose-regulated and heat shock proteins) (1). In view of the likely protective function of these other stress proteins in promoting cell survival in response to environmental challenges (35), we speculated that ORP150 might behave similarly. The role of MPs as scaven- 


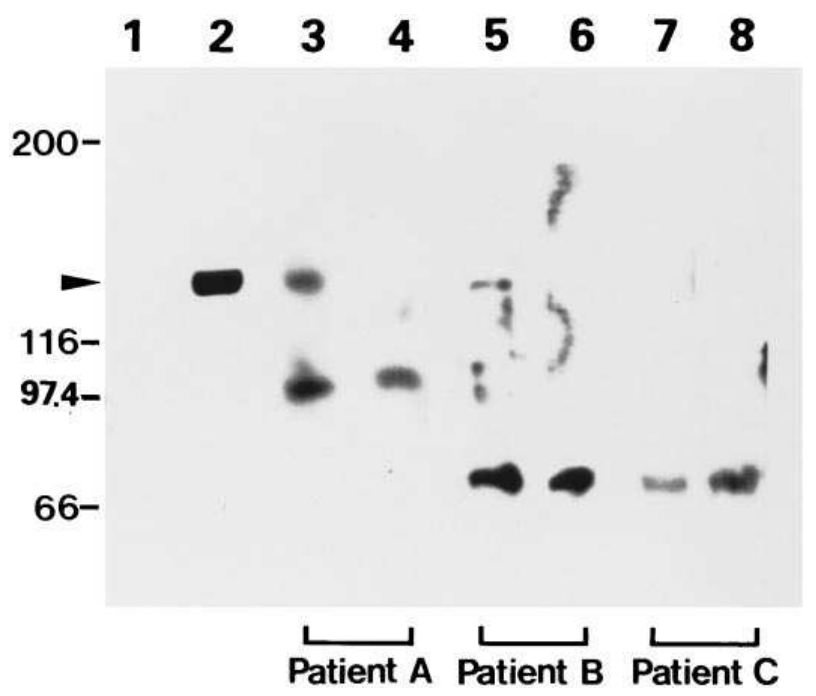

Figure 8. Detection of autoantibody to ORP150 in the plasma of patients with atherosclerosis. Protein extract from MPs $(5 \mu \mathrm{g})$ cultured under normoxic (lane 1) or hypoxic (lane 2) conditions for $24 \mathrm{~h}$ was subjected to immunoblotting using rabbit anti-human ORP150 antibody. Other lanes of the blot, containing extract of hypoxic MPs, were reacted with serum prepared from three patients (see below) in the absence (lanes 3,5, and 7) or presence (lanes 4,6, and 8 ) of rabbit anti-human ORP150 antibody (200 ng/ml). Patient A was a 73-yr-old male with angina pectoris and cerebral infarction (lanes 3 and 4). Patient B was a 65 -yr-old male with cerebral infarction (lanes 5 and 6 ). Patient $\mathrm{C}$ was a 74-yr-old female without any evidence of atherosclerosis ( 7 and 8$)$. In each case, atherosclerosis was evaluated by angiography of the thoracic and abdominal aorta and cerebral arteries. The migration of simultaneously run molecular weight markers is shown on the left side of the gel.

gers of cellular debris and orchestrators of vascular remodeling suggests their facile adaptation to stressful stimuli $(36,37)$.

Our previous analysis of ORP150 provided certain clues as to how this inducible polypeptide might have cytoprotective properties. First, it has two HSP70 family-specific signatures, structural motifs likely to have ATPase activity. Second, the presence of a $\mathrm{COOH}$-terminal KNDEL sequence suggests ORP150 may be retained in the endoplasmic reticulum, a location in which other stress proteins are found (38) and where it is ideally positioned to facilitate protein folding. Our recent studies have confirmed localization of this stress protein in the endoplasmic reticulum by immunocytochemical analysis (5). Further insight into the mechanisms through which ORP150 exerts its effects is the ability of antioxidants, such as probucol or $\mathrm{N}$-acetylcysteine, to protect MPs from death after suppression of ORP150 expression in a hypoxic environment with oxidized LDL. These data imply that ORP150 bound to the endoplasmic reticulum may have cytoprotective properties, potentially related to the oxidant status of the cell. Expression of ORP150 in macrophages under ischemic microenvironments promotes cell survival and thus is likely to be critical in enabling macrophages to redirect their biosynthetic activities in hypoxia. This results in events such as the elaboration of growth and/or migratory factors central to stimulation of angiogenesis in response to hypoxia $(39,40)$.

The presence of autoantibodies to ORP150 in the plasma of patients with severe atherosclerosis also emphasizes the
Table I. ELISA for Anti-ORP150 Autoantibody in Patient Sera

\begin{tabular}{cllr}
\hline Case & Age/sex & \multicolumn{1}{c}{ Clinical feature } & Dilution \\
\hline $1^{*}$ & $73 / \mathrm{M}$ & Angina \& cerebral infarction & 640 \\
$2^{*}$ & $65 / \mathrm{M}$ & Cerebral infarction & 640 \\
3 & $60 / \mathrm{F}$ & Hypertension \& ASO & 1,280 \\
4 & $68 / \mathrm{M}$ & ASO & 640 \\
5 & $63 / \mathrm{M}$ & Dissecting aneurysm & 320 \\
6 & $61 / \mathrm{M}$ & Hypertension & 320 \\
$7 *$ & $74 / \mathrm{F}$ & Age-matched control & $<80$ \\
8 & $54 / \mathrm{M}$ & Age-matched control & 160 \\
9 & $80 / \mathrm{F}$ & Age-matched control & 160 \\
10 & $66 / \mathrm{M}$ & Age-matched control & $<80$ \\
11 & $68 / \mathrm{M}$ & Age-matched control & $<80$ \\
& & & \\
\hline
\end{tabular}

The ORP150-enriched fraction was absorbed to wells of ELISA plates to which anti-human ORP150 IgG had been bound. After incubation at $37^{\circ} \mathrm{C}$ for $1 \mathrm{~h}$, plates were washed three times with PBS containing Tween $20(0.05 \%)$ and incubated for $1 \mathrm{~h}$ at $37^{\circ} \mathrm{C}$ with patient sera as indicated. Plates were then washed four times, sites of primary antibody visualized using peroxidase-conjugated anti-human $\mathrm{IgG}$, and $\mathrm{OD}_{495}$ was measured. The background in each serum sample was obtained by preincubating with anti-rat ORP150 IgG. Anti-ORP150 autoantibody in patient serum was titrated to a dilution at which $\mathrm{OD}_{520}=0.2$ was obtained. *Cases 1,2 , and 7 in this table correspond to patients A, B, and $\mathrm{C}$ in Figure 8, respectively. ASO, arteriosclerosis obliterans.

presence of this protein in vascular lesions. Although we have not performed a detailed analysis of every tissue for ORP150 at this time, the association of autoantibodies with severe vascular disease suggests a possible sequence of events: ORP150 induction occurs in vascular cells, especially macrophages in atherosclerotic lesions. During the course of lesion formation, certain cells that express ORP150 die (such as degenerating macrophages, observed in atherosclerotic lesions) or catastrophic events such as plaque rupture (41) disrupt a large number of cells, releasing their contents and allowing the host to mount an antibody response. Consistent with these data, autoantibody to other stress proteins has been detected in patient plasma (42). This may account for the other bands visualized when patient sera were reacted with lysates of hypoxic, vs lack of reactivity with normoxic, extracts of mononuclear phagocytes (Fig. 8).

In summary, our study provides evidence that a novel hypoxia-inducible protein, ORP150, is present in the atherosclerotic vessel wall, especially in mononuclear phagocytes. The cytoprotective role of macrophage ORP150 in the setting of oxygen depletion and the presence of oxidized LDL suggests that it may be an important survival factor allowing MPs to carry on their role of tissue remodeling and scavenging under environmentally challenging conditions.

\section{Acknowledgments}

We thank Ms. M. Shimomura and R. Manabe for their secretarial assistance.

This work was supported by a Grant-in-Aid from the Ministry of Education, Science and Culture of Japan, a Research Grant for cardiovascular disease from the Ministry of Health and Welfare of Japan, and grants from the Public Health Service (HL42507, HL52609, PERC). 


\section{References}

1. Wilson, R.E., and R.M. Sutherland. 1989. Enhanced synthesis of specific proteins, RNA, and DNA caused by hypoxia and reoxygenation. Int. J. Radiat. Oncol. Biol. Phys. 16:957-961.

2. Maeda, Y., M. Matsumoto, T. Ohtsuki, K. Kuwabara, S. Ogawa, O. Hori, D.Y. Shui, T. Kinoshita, T. Kamada, and D.M. Stern. 1994. Hypoxia-reoxygenation mediated induction of Interleukin-6 in cultured rat astrocytes and expression in ischemic gerbil brain: a paracrine mechanism enhancing neuron survival. J. Exp. Med. 180:2297-2308.

3. Hori, O., M. Matsumoto, K. Kuwabara, Y. Maeda, H. Ueda, T. Ohtsuki, T. Kinoshita, S. Ogawa, D.M. Stern, and T. Kamada. 1996. Exposure of astrocytes to hypoxia/reoxygenation enhances expression of glucose-regulated protein 78 facilitating astrocyte release of the neuroprotective cytokine Interleukin 6. J. Neurochem. 66:973-979.

4. Kitagawa, K., M. Matsumoto, M. Tagaya, K. Kuwabara, R. Hata, N. Handa, R. Fukunaga, K. Kimura, and T. Kamada. 1991. Hyperthermia-induced neuronal protection against ischemic injury in gerbils. J. Cereb. Blood Flow Metab. 11:449-452.

5. Kuwabara, K., M. Matsumoto, J. Ikeda, O. Hori, S. Ogawa, Y. Maeda, K. Kitagawa, N. Imuta, K. Kinoshita, D.M. Stern, et al. 1996. Purification and characterization of a novel stress protein, the $150 \mathrm{kDa}$ oxygen-regulated protein (ORP150), from cultured rat astrocytes and its expression in ischemic mouse brain. J. Biol. Chem. 271:5025-5032.

6. Koga, S., S. Ogawa, K. Kuwabara, J. Brett, L.A. Leavy, J. Ryan, Y. Koga, J. Plocinski, W. Benjamin, D.K. Burns, and D.M. Stern. 1992. Synthesis and release of Interleukin 1 by reoxygenated human mononuclear phagocyte. $J$. Clin. Invest. 90:1007-1015.

7. Ogawa, S., H. Gerlach, C. Esposito, A.P. Macaulay, J. Brett, and D.M. Stern. 1990. Hypoxia modulates the barrier and coagulant function of cultured bovine endothelium. J. Clin. Invest. 85:1090-1098.

8. Hori, O., M. Matsumoto, Y. Maeda, H. Ueda, T. Ohtsuki, D.M. Stern, T. Kinoshita, S. Ogawa, and T. Kamada. 1994. Metabolic and biosynthetic alterations in cultured astrocytes exposed to hypoxia/reoxygenation. J. Neurochem. 62:1489-1495.

9. Basu, S.K., J.L. Goldstein, R.G.W. Anderson, and M.S. Brown. 1976. Degradation of cationized low density lipoprotein and regulation of cholesterol metabolism in homozygous familial hypercholesterolemia fibroblasts. Proc. Natl. Acad. Sci. USA. 73:3178-3182.

10. Endemann, G., L.W. Stanton, K.S. Madden, C.M. Bryant, R.T. White, and A.A. Protter. 1993. CD36 is a receptor for oxidized low density lipoprotein. J. Biol. Chem. 268:11811-11816.

11. Laemmli, U. 1970. Cleavage of structural proteins during the assembly of the head of bacteriophage T4. Nature (Lond.). 277:680-685.

12. Fong, L.G., S. Parthasarathy, J.L. Witzum, and D. Steinberg. 1987. Nonenzymatic oxidative cleavage of peptide bonds in apoprotein B-100. $J$. Lipid Res. 28:1466-1477.

13. Steinbrecher, U.P., S. Parthasarathy, D.S. Leake, J.L. Witzum, and D. Steinberg. 1984. Modification of low density lipoprotein by endothelial cells involves lipid peroxidation and degeneration of low density lipoprotein phospholipids. Proc. Natl. Acad. Sci. USA. 81:3883-3887.

14. Tam, J.P. 1989. Synthetic peptide vaccine design: synthesis and properties of a high-density multiple antigenic peptide system. Proc. Natl. Acad. Sci. USA. 86:9084-9088.

15. Cooper, H.M., and Y. Paterson. 1991. Production of antibodies. In Current Protocol in Immunology. J.E. Coligen, A.M. Kruisbeek, D.H. Margulies, E.M. Shevach, and W. Strober, editors. John Wylie \& Sons, Inc., New York. 2.4.1-2.4.7

16. Towbin, H., T. Strachelin, and J. Gordon. 1979. Electrophoretic transfer of protein from polyacrylamide gels to nitrocellulose sheets; procedures and some applications. Proc. Natl. Acad. Sci. USA. 76:4350-4354.

17. Lowry, O., N.J. Rosenbrough, L.A. Farr, and R.J. Randall. 1951. Protein measurement with the Folin phenol reagent. J. Biol. Chem. 193:265-275.

18. Shiratori, Y., K.A. Okwu, and I. Tabas. 1994. Free cholesterol loading of macrophages stimulates phosphatidylcholine biosynthesis and up-regulation of CTP: phosphocholine cytidylyltransferase. J. Biol. Chem. 269:11337-11348.

19. Chirgwin, J.M., A.E. Przybyla, R.J. MacDonald, and W.J. Rutter. 1979. Isolation of biologically active ribonucleic acid from sources enriched in ribonuclease. Biochemistry. 18:5294-5299.
20. Stary, H.C., A.B. Chandler, R.E. Dinsmore, V. Fuster, S. Glasgov, W. Insull, M.E. Rosenfeld, C.J. Schwartz, W.D. Wagner, and R.W. Wissler. 1995. A definition of advanced types of atherosclerotic lesions and a histological classification of atherosclerosis - a report from the committee of vascular lesions of council on atherosclerosis, American Heart Association. Arterioscler. Thromb. Vasc. Biol. 15:1512-1531.

21. Skalli, O., P. Ropraz, A. Trzeciak, G. Benzonana, D. Gillessen, and G. Gabbiani. 1986. A monoclonal antibody against $\alpha$-smooth muscle actin: a new probe for smooth muscle differentiation. J. Cell. Biol. 103:2787-2796.

22. Sanger, A., S. Nicklen, and A. Coulson. 1977. DNA sequencing with chain terminating inhibitors. Proc. Natl. Acad. Sci. USA. 74:5463-5467.

23. Hirota, S., M. Imakita, K. Kohri, A. Ito, E. Morii, S. Adachi, H.M. Kim, Y. Kitamura, C. Yutani, and S. Nomura. 1993. Expression of osteopontin messenger RNA by macrophages in atherosclerotic plaques. Am. J. Pathol. 143: 1003-1008.

24. Falini, B., L. Flenghi, S. Pileri, M. Gambacorta, B. Bigerna, H. Durkop, F. Eitelbach, J. Thiele, R. Pacini, A. Cavaliere, et al. 1993. PG-M1: a new monoclonal antibody directed against a fixative-resistant epitope on the macrophagerestricted form of CD68 molecule. Am. J. Pathol. 142:1359-1372.

25. Matsuo, N., S. Ogawa, Y. Imai, T. Takagi, M. Tohyama, D.M. Stern, and A. Wanaka. 1995. Cloning of a novel RNA binding polypeptide (RA301) induced by hypoxia/reoxygenation. J. Biol. Chem. 270:28216-28222.

26. Kuwabara, K., D.J. Pinsky, A.M. Schmidt, C. Benedict, J. Brett, S Ogawa, M.J. Broekman, A.J. Marcus, R.R. Sciacca, and M. Michalak. 1995. Calreticulin, an antithrombotic agent which binds to vitamin $\mathrm{K}$-dependent coagulation factors, stimulates endothelial nitric oxide production, and limits thrombosis in canine coronary arteries. J. Biol. Chem. 270:8179-8187.

27. Barker, S.G., A. Talbert, S. Cottam, P.A. Baskerville, and J.F. Martin. 1993. Arterial intimal hyperplasia after occlusion of the adventitial vasa vasorum in the pig. Arterioscler. Thromb. 13:70-77.

28. Martin, J.F., R.F. Booth, and S. Moncada. 1991. Arterial wall hypoxia following thrombosis of the vasa vasorum is an initial lesion in atherosclerosis. Eur. J. Clin. Invest. 21:355-359.

29. Heistad, D.D., M.L. Marcus, G.E. Larsen, and M.L. Armstrong. 1982 Role of vasa vasorum in nourishment of the aortic wall. Am. J. Physiol. 240: 781-787.

30. Nakata, Y., and S. Shionoya. 1966. Vascular lesions due to obstruction of the vasa vasorum. Nature (Lond.). 212:1258-1259.

31. Crawford, D.W., and D.H. Blankenhorn. 1991. Arterial wall oxygenation, oxyradicals, and atherosclerosis. Atherosclerosis. 89:97-108.

32. Santilli, S.M., V.D. Fiegel, and D.R. Knighton. 1992. Changes in the aortic wall oxygen tensions of hypertensive rabbits. Hypertension and aortic wall oxygen. Hypertension (Dallas). 19:33-39.

33. Santilli, S.M., V.D. Fiegel, and D.R. Knighton. 1993. Alloxan diabetes alters the rabbit transarterial wall oxygen gradient. J. Vasc. Surg. 18:227-233.

34. Heacock, C.S., and R.M. Sutherland. 1986. Induction characteristics of oxygen regulated protein. Int. J. Radiat. Oncol. Biol. Phys. 12:1287-1290.

35. Pelham, R.B.H. 1986. Speculation on the functions on the major heat shock and glucose-regulated proteins. Cell. 46:959-961.

36. Libby, P., and S.K. Clinton. 1993. The role of macrophage in atherogenesis. Curr. Opin. Lipidol. 4:355-363.

37. Ross, R. 1993. The pathogenesis of atherosclerosis: a perspective for 1990s. Nature (Lond.). 362:801-809.

38. Lee, A.S. 1992. Mammalian stress response: induction of the glucose regulated protein family. Curr. Opin. Cell Biol. 4:267-273.

39. Knighton, D.R., T.K. Hunt, H. Scheuenstuhl, B. Halliday, Z. Werb, and M. Banda. 1983. Oxygen tension regulates the expression of angiogenesis factor by macrophages. Science (Wash. DC). 221:1283-1285.

40. Kuwabara, K., S. Ogawa, M. Matsumoto, S. Koga, M. Clauss, D.J. Pinsky, P. Lyn, J. Leavy, L. Witte, J. Joseph-Silverstein, et al. 1995. Hypoxia-mediated induction of acidic/basic fibroblast growth factor and platelet-derived growth factor in mononuclear phagocytes stimulates growth of hypoxic endothelial cells. Proc. Natl. Acad. Sci. USA. 92:4606-4610. $30-42$.

41. Falk, E. 1992. Why do plaques rupture? Circulation. 86(suppl. III):

42. Xu, Q., J. Willeit, M. Marosi, R. Kleindienst, F. Oberhollenzer, S. Kiechl, T. Stulnig, G. Luef, and G. Wick. 1993. Association of serum antibodies to heat-shock protein 65 with carotid atherosclerosis. Lancet (N. Am. Ed.). 341: 255-259. 